\title{
The Significance of Colloidal Rare Earth Elements and Yttrium in Deep-Sea Pore Waters
}

\author{
SOPHIE PaUl ${ }^{1}$ Katja SCHMIDT $^{2}$ ERIKA Kurahashi $^{1}$
} ANDREA KOSCHINSKY ${ }^{1}$

${ }^{1}$ Jacobs University Bremen, 28759 Bremen, Germany

(*correspondence: s.paul@jacobs-university.de)

${ }^{2}$ German Federal Institute for Geosciences and Natural Resources, 30655 Hannover, Germany

Rare earth elements and yttrium (REY) are frequently used as paleoceanographic proxies. A prerequisite for the usability of shale normalized (SN) REY patterns is the preservation of the primary signature in the archive, e.g., carbonate or $\mathrm{Ca}$ phosphate. Fractionation during particlesolution interaction or redox reactions can be seen in the REYSN patterns and in the anomalous behavior of e.g., the redox sensitive Ce. Previous research [e.g., 1] has shown that $\mathrm{Ca}$ phosphates incorporate REY without major fractionation from ambient pore water. Therefore, the pore water REYSN pattern determines the archive's REY SN $_{\text {pattern. }}$ Understanding pore-water REY cycling is crucial for the understanding of REY cycling in the marine environment and its influence on the oceanic REY budget, e.g., in form of a benthic flux, and when using REY as paleoenvironmental proxies in sedimentary archives. Here we present various REY bottom water and oxic pore-water depth profiles and SN patterns from the Clarion Clipperton Zone, central equatorial Pacific for the upper ca. $15 \mathrm{~cm}$. REY concentrations are slightly elevated at the sediment-water-interface, suggesting release during the remineralization of organic matter, similar to other trace metals. This also suggests a diffusive flux of REY from the pore water to the seawater. Sequential filtration allowed us to compare the dissolved $(<0.2 \mu \mathrm{m})$ and soluble $(<0.02 \mu \mathrm{m})$ REY pool. Only ca. $20 \%$ of REY are found in the soluble pool, which shows that the main association of REY is in the colloidal phase, potentially Mn and Fe colloids. In the pore-water dissolved pool, REYSN either show seawater-like patterns with heavy REY enrichment, a pronounced negative $\mathrm{Ce}$ anomaly, and positive $\mathrm{Y}$ anomaly or an enrichment of middle REY over the light and heavy REY and only a small negative Ce anomaly. In the soluble pool, patterns show similar enrichment trends. Patterns reflect variable degrees of sediment-pore water interaction and hence alteration of seawater signature. Concentrations and SN patterns vary between sites and suggest that many open questions remain about the alteration of REY in pore waters related to early diagenesis.

[1] Paul et al. (2019) Geochim. Cosmochim. Acta 251, 56-72. 